International Journal of Business Management and Economic Review

Vol. 3, No. 05; 2020

ISSN: 2581-4664

\title{
MANAGING CONFLICTS IN PUBLIC HOSPITALS IN TANZANIA: THE UNDERLYING CAUSES OF CONFLICTS
}

\author{
Ngirwa, $C$. \\ Institute of Social Work \\ Jaensson, J-E., \\ Open University of Tanzania, \\ Barongo, F. , \\ Mzumbe University \\ http://doi.org/10.35409/IJBMER.2020.3207
}

\begin{abstract}
Conflicts can be viewed as a situation of competition or incompatibility between people, organizations or nations and the parties in conflict are aware of the situation. Employing different strategies to manage conflict situations would enhance job performance. Drawing from the conflict management strategies, this study explored the underlying causes of conflicts between medical doctors and the government in public hospitals in Tanzania. The qualitative findings from 22 medical doctors from the two public hospitals (Muhimbili National Hospital and Dodoma Regional Referral Hospital) revealed that poor working facilities, unavailability of medicines, patients overcrowding, shortage of staff (Doctors), remunerations, doctors promotions, medical insurance scheme, hardship allowance, overtime allowance and call allowances were the main causes of conflict between medical doctors and the government. The findings suggest that despite of the scarcity of resources on the side of the government, it could have conducted a series of meetings to discuss and lay down some strategies to manage the conflict in public hospitals and improve working environment that would engender favorable doctors' career-wellbeing.
\end{abstract}

Keyword:conflict, conflict management, compromise and integrating style of managing conflict.

\section{INTRODUCTION}

When individuals or groups or organizations, or even nations have different opinions on a related subject matter, their relationship will result in conflict (Jaden, 2018). Relationships among such entities may become inconsistent when two or more of them desire a similar resource that is in short supply; when they have parted exclusive behavioral preferences regarding their joint action; or maybe when they have different attitudes, values, beliefs, and skills (Chigozie, 2017). Conflict may be considered as when people perceive the same thing in different ways (Okoro et al, 2018) and Rahim (2011; p15) defines it as "a situation in which the conditions, practices, or goals for the different participants are inherently incompatible". 


\section{International Journal of Business Management and Economic Review}

Vol. 3, No. $05 ; 2020$

ISSN: 2581-4664

Conflicts can be between people, organizations, nations, political parties, and other entities (Rahim, 2011). These conflicts can be as a result of scarce resources, status inconsistencies, incompatible goals and time horizons, overlapping authority, task interdependencies, incompatible evaluation or reward systems, and many more other causes (Agwu, 2013). Recently, there have been renewed interest and significant changes in the study of conflict in social and organizational contexts. Conflicts are unavoidable and they are neither good nor bad (Jaden, 2018). The key element is on how to understand and respond to conflict (Rahim, 2011). The parties involved in a conflict, establish the meaning of conflict with the ultimate results being determined by the feelings, beliefs, and values of the involved (Ebtesam, 2018). We need conflict for the functioning of the organization in general, whereby the main concern is the management of the magnitude of the conflict that brought about good performance. Managers in most of the organizations spend most of their considerable time managing conflicts and their management becomes crucial to the normal execution of their duties (Ojo \& Abolade, 2014).

Management of conflict is extremely important for the functioning of organizations and the personal, cultural, and social development of human beings (Rahim, 2011). Constructive and creative conflict management is a real challenge and a goal of any professional who is genuinely interested in assisting others and the organization as a whole, in changing unfavorable conflict situations into positive, cooperative and relatively peaceful directions. This way of maintaining a reasonable number of conflicts, promotes motivation, enhances morale, and promotes an individual's job performance and organizational growth (Al-Hamdan et al. 2011).

According to Rahim (2011) conflict management involves designing better strategies to minimize the dysfunctions of conflict and enhance the constructive functions to optimize the learning and effectiveness of an organization. Conflict management does not necessarily imply avoidance, reduction, or termination of the conflict. It involves designing effective strategies to minimize/reduce the dysfunctions of conflict and enhancing the constructive functions of conflict to enhance the learning and effectiveness of an organization (Al-Hamdan et al. 2011). This calls for a need to manage well conflicts in work organizations. It has to entail designing relevant tactics to reduce the negative effects of conflict and improve the productive functions of conflict to develop learning and efficiency in an organization (Rahim, 2011). Warioba, (2008) indicated that conflicts can be managed using diverse styles which are Integrating, Obliging, Compromising, Dominating, and Avoiding. In integrating style, there is a high concern for self and others as it involves collaboration between the parties and each desire to satisfy fully the concerns of all the parties; whereby the intention is to solve the trouble by clarifying differences rather than by accommodating various points of view (Rahim, 2011). In an obliging style, it indicates low concern for self and high concern for others, placing the opponent's interest above your own (Rahim, 2011). In a dominating style, it indicates a high concern for self and low concern for others, meaning it is when one seeks to satisfy his or her interests regardless of the impact on the other parties to the conflict (Al-Hamdan et al. 2011). In avoiding style, it indicates low concerns of self and others, where one just tries to ignore a conflict and avoiding others in conflict (Rahim, 2011). The last but not least is the compromising style, whereby it indicates intermediate in concern for self and others, it is a situation in a conflict where each party is 


\section{International Journal of Business Management and Economic Review}

Vol. 3, No. $05 ; 2020$

ISSN: 2581-4664

willing to give up something and finally gain mutually acceptable decisions (Al-Hamdan et al, 2011).

Accordingly, Medical doctors are important resources for effective performance of hospitals. However, medical doctors in public hospitals around the world have been involved in conflicts with the government several times, which affect their endeavors and hospitals' performance in general (Isangula, 2012; Mhegera, 2012). Shaw et al. (2011) believe that it is healthier for the employer to manage the conflict due to its effects on job performance although there are other factors affecting job performance.

Like other countries of the world, Tanzania has been facing medical doctors' strikes since independence (e.g., in 1900s, 2005/06 and the 2012 strike). These strikes were said to be on and off indicating that the government might have no effective ways of managing them and may be the medical doctors demands were unrealistic or maybe their causes haven't been identified. Nevertheless, the on and off strikes indicated that the government may be ineffective in managing conflicts in public hospitals (Isangula, 2012). Another may think that it might be the employer using empty promises to the affected part (medical doctors) and that when it fails to fulfill the promises, the conflicts arise again. The performance of medical doctors in these public hospitals is highly affected by the existing conflicts, as the government tries to manage conflict in the health sector and public hospitals in particular (Kazimoto, 2013).

Despite the employer's efforts in managing conflicts whenever arose, still public hospitals have been experiencing medical doctors strikes and that has made thehealth service provision in the whole country to deteriorate (Kijo-Bisimba, 2012). In the process of managing any conflict situation, causes of the conflict have to be known first. Without knowing the cause of conflict, it would be difficult to manage it. The study aimed at unfolding the possible causes of conflicts in public hospitals in Tanzania and suggesting ways on how such conflicts can be managed.

Understanding the underlying causes of conflicts in health sector would be a starting point towards effective management of conflicts, Doctors wellbeing and hospitals' performance in general.

\section{LITERATURE REVIEW}

\section{Types of Conflict}

The classification of conflict is often made based on the antecedent conditions that lead to conflict. Conflict may originate from several sources, such as tasks, values, goals, and so on (Warioba, 2008). It has been found appropriate to classify the conflict based on these sources for the proper understanding of its nature and implications. Substantive conflicts relate to disagreements about tasks, policies, and other business issues and are called task conflict, substantive conflict, or cognitive conflict. Also, another type of conflict is Affective conflict; it is generally caused by the negative reactions of organizational members, i.e. Personal attacks of group members, racial disharmony, sexual harassment, etc. Another type is process conflict, which is negatively associated with group performance and satisfaction and it is how different 


\section{International Journal of Business Management and Economic Review}

Vol. 3, No. 05; 2020

ISSN: 2581-4664

tasks should be performed, task assignment, the responsibility to complete specific tasks, etc. (Rahim, 2011).

\section{The Contingency Theory of Conflict Management}

The contingency theory of conflict management was developed by Cameron in 1997 when the first article about the theory was published and as it's based on the excellence theory of public relations that was developed by Grunig and Grunig's, (1992) and Grunig and Hunts, (1984).

The theory of conflict management allows for the comprehensive analysis of the conflict situation before suggesting a better solution for the same, taking into account the two situations which are decision quality and decision acceptance. The quality of the decision is the extent to which it will affect essential group practices and the acceptance of the decision refers to the degree of commitment of employees desired for its execution. The effective management of conflicts depends much on the matching of the approach and the situations.

The conflict situation indeed has to be thoroughly analyzed for a better conflict management style as there is no better way of managing conflict at workplaces (Saranya, 2016). The theory continues to suggest that a mechanistic design is suitable for organizations that respond to the unchanging environment, but an organic design is appropriate for organizations that respond to the changing environment (Rahim, 2011). This is to say all organizations are open systems as they interact with the dynamic environment and conflicts arise in this process. The greater the correspondence between the design and environment, the more effective is the management of conflict and the greater is the job performance and the adoption of organic-adaptive structures are recommended by the organizational development that encourages effective management of conflict. This means that the organic-adaptive structure enables the organization to scan the environment in the process of managing existing conflicts.

The challenge that faces the contingency theory of conflict management is its applicability in all spheres of conflict and concerning this study. The applicability of the contingency theory of conflict management in health sector conflicts is the theoretical gap that has to be filled with the study (Rahim, 2011). This theory is linked to the current study in the sense that it calls for a thorough analysis of conflict situations in public hospitals to suggest a relevant approach to managing conflict. The 2012 medical doctor's strike was the extension of the 2005/06 medical doctor's strike and the way it was handled had called for the applicability of this theory into the current study.

\section{Causes of Conflicts}

Several types of conflicts occur in organizations and their causes may vary according to the situation at that particular point in an organization. Conflicts may be as a result of roles employees perform in organizations, interpersonal conflicts, task conflicts and as a result of scarce resources in an organization. Also, poor communication, unfair treatment of employees, inadequate in the reward system of the organization, favoritism and nepotism (Isa, 2015) and Khan et al, (2017).

\section{Role conflicts}




\section{International Journal of Business Management and Economic Review}

Vol. 3, No. 05; 2020

ISSN: 2581-4664

This is when there are irreconcilable demands of an individual in relation to the activities he is doing or by virtue of his position. Employees experience this type of conflict when they feel there are in the middle of a situation pulled in different directions as they are responding to various forces by virtue of their positions. These two incompatible roles places an individual in a conflict situation may place an individual in a difficult conflict situation (Isa, 2015).

\section{Task Conflicts}

In a working environment, task conflict arises when two parties are unable to complete an assigned activity or duty due to their differences in needs, behavior or attitudes this cause of conflict may be over rules and regulations, organisational policies and procedures, scarce resources and even work methods or any other ways of task accomplishment (Blank, 2020).

\section{Inadequate in the reward system of the organization}

These are incentives programs that aim at encouraging employee engagement and productivity by giving them financial and non-financial rewards for a job well done (Khan et al, 2017). The main purpose of having these reward systems in respective organizations is to attract good employees to the work organization, retain existing employees, stimulating their inner drives to continue doing a good job to increase productivity.

\section{Favoritism and Nepotism}

This is a one of the causes of conflict at workplaces in most of the work organizations. This is showing favor or preferential unfair treatment to an individual at work place just because he is your relative or close family member (Isa, 2015). This happens in most of the organizations where family members are hired.

\section{Unfair treatment of employees at workplace}

Unfair treatment of an employee decreases their motivation and lowers employee's job performance. When an individual feels that he is treated unfairly in an organization, his working spirit is lowered and even the work morale is reduced (Blank, 2020). This can be a cause of conflicts in the respective organizations.

\section{Scarce Resources}

This is when the organization has limited availability of resources in combination with greater production demands. The resources could be human and non-human resources. This may become a cause of conflict when the job demands more than what employees can offer as a result of not having enough resources (Khan et al, 2017).

\section{Poor communication}

This is one of the main causes of conflict in work organizations. This is as a result failure to communicate. This is when a supervisor assigns a task to a subordinate and fails to communicate the same to the subordinate (Blank, 2020). Failure to communicate at the workplace causes employees to have incorrect perceptions and strains workplace gossip and destroys organization image. Poor communication at the workplace causes conflict and also lowers employee's performance and employee morale (Isa, 2015). 
International Journal of Business Management and Economic Review

Vol. 3, No. 05; 2020

ISSN: 2581-4664

\section{Empirical Literature Review}

A study by Ayub et al. (2017) on Personality Traits and Conflict Management Styles in predicting Job Performance and Conflict, a survey study conducted in Saudi Arabia with a sample of 153 employees revealed that Agreeable persons perceive less conflict and Extraverts are more likely to use Integrating, Obliging, Compromising, and Avoiding styles. Emotionally Stable people opt for Integrating while Neurotics opt for dominating style. Conscientiousness, Openness, and Emotional Stability have a direct effect on performance, but the interactions between Conflict and Conflict Management Styles determine the relationship between personality traits and performance. The findings propose the application or use of different styles basing on personality traits. This study differs from the current study in the sense that it included the personality traits together with conflict management styles as independent variables while the current study does not involve the personality traits. Also, the study was not conducted in public hospitals.

Pitsillidou et al. (2018) conducted a study on conflict management among health professionals in hospitals of Cyprus with a sample of 300 health professionals from six different hospitals. This quantitative study using descriptive data analysis revealed that the causes of conflict were heavy workload, low pay, and varying instructions from different leaders. To deal with the conflict, $73.2 \%$ of the participants reported using avoidance, $54.2 \%$ engaged in negotiation for mutual benefit, and $40.5 \%$ cited compromise as a method. The findings suggest that identifying how conflicts are managed contributes to the smooth functioning of organizations, and it improves the effectiveness of the services provided. This study differs from the current study in the sense that it was conducted in an environment different from the current study and that it has involved nurses while this has medical doctors in place.

Hossain (2017) in a study on the Impact of Organizational Conflict on Employees' Performance in Private, Commercial Banks of Bangladesh investigates the connection between employee performance and organizational conflict that considerably affect employees' performance in the banking sector of Bangladesh. A sample of 200 respondents was analyzed and revealed that there is a considerable relationship between organizational conflict and employee's performance and that the conflict management styles should be highly utilized to bring conflicts to normal for employee's performance. The study has focused on the same facets as the current study but the study has focused on the impact of organizational conflict on employee performance in the banking sector that has different needs comparing to the health sector and especially public hospitals and the way they handle conflicts management and how conflicts influence job performance.

Ogaga (2017) conducted a study on the impact of organizational conflict on the employee's performance; evidence from Dangote Cement Plc, Gboko Plant. Using Pearson correlation and the Logit estimation method, it was revealed that of the three types of conflict only relationship conflict has a significant effect on the performance of employees and also that whilst relationship conflict adversely affects performance, both task and process conflicts have a positive influence on the output of workers. The study, therefore, suggests that the policymakers 


\section{International Journal of Business Management and Economic Review}

Vol. 3, No. $05 ; 2020$

ISSN: 2581-4664

and the management of organizations should efficiently and effectively set up conflict resolution mechanism by eliminating all friction that may arise from the three types of organizational conflict if they want to achieve rapid growth in the enterprise. Those conflicts that affect performance positively should be encouraged. The study aimed at testing the impact of the three types of conflict (relationship, task, and process) on the performance of employees while the current study is focusing on the conflict management on the medical doctor's job performance in public hospitals.

Chigozie 2017 conducted a study on the Impact of Organizational Conflict on Employee Job Performance in Selected Hotels (in Lagos Nigeria) with a sample of 110 respondents. Using inferential statistics and hypotheses were tested in Chi-square statistics, it was revealed that unclear responsibilities, poor reward system, and lack of group cohesiveness, are responsible for organizational conflicts; with the consequential impact on employee job commitment, service quality, customer satisfaction, and organizational performance, whereas outcomes generate influence on employee job satisfaction and job performance, thus creating turnover intentions and further generating organizational conflict. The research suggests a strengthened supportive mechanism of the human resource department and forestalling distrust among working groups, which will reduce the impact of work stressors on psychological states. This study is different from the current study as it was conducted in selected hotels while the current study is on public hospitals involving medical doctors.

Jaden 2018 did a study of conflict management styles and employee performance in public hospitals in Nyeri County, Kenya. The study comprised 166 respondents and used descriptive statistics, correlation statistics, and inferential statistics in the Statistical Package for Social Sciences software (SPSS). It was revealed that public hospitals, mainly use compromising style, avoiding style, and dominating style because of their advantageous side. The findings revealed an integrating style and accommodating style like the styles hardly used among the respondents. The findings indicated that the compromising style, dominating style, and avoiding style has a significant relationship with employee performance in the work environment and employee performance is affected when conflicts are not managed. The study focused on all health workers (doctors, nurses, and clinical officers) in selected public hospitals while the current study has focused on medical doctors alone as the source of the strike between medical doctors and the government.

Another research was done by Isangula (2012) revealed that the overextended on-and-off strike in Tanzania in early 2012 as a result of unfruitful negotiations between the government and the doctors. Civil society organizations referred to as 'activists' involved with advocacy for health-related and human rights issues intervened largely by using several advocacy strategies. Despite many efforts, the achievements were below expectations. Also, it tries to share the advocacy strategy utilized by civil society organizations 'activists' during a doctors' strike in the country, achievements and setbacks, then provides recommendations that may be applied should a need arise in the future. The study focused on the role played by civil society organizations (activists) during and after the strike also the successes and setbacks of their involvement during 
Vol. 3, No. 05; 2020

ISSN: 2581-4664

the strike. The study has addressed the general cause of the conflict without elaborating on the specific causes while the current study has focused on the specific causes of the same conflict.

\section{METHODOLOGY}

In this study, qualitative research design was used. Data were collected from the medical doctorsof the two public hospitals,(Muhimbili National hospital and Dodoma Referral Regional Hospital). Purposive and snowball sampling techniques were used in the study during the interviewing of participants. The population of the study included all medical doctors from the study area who were present before the year 2012 assuming that they were present before and during the strike. The hospital administrations provided a list of 165 medical doctors from the Muhimbili national hospital and 26 medical doctors from Dodoma regional referral hospital respectively. A total of 22 medical doctors were interviewed to a point of saturation. All interviews were recorded with the consent of interviewees and then transcribed as soon as possible after the respective interview has finished.

\section{RESULTS AND DISCUSSION}

In analyzing qualitative data, the thematic data analysis technique was used to analyze qualitative data and use thematic statements to present findings.

The study aimed at identifying the possible causes of conflict between the medical doctors and the government and suggesting possible solutions or measures for the causes. The assumption was that the understanding of the causes of the conflict would enhance the theoretical contribution on what transpired during and after the medical doctor's strike.

The categories were developed from the thematic analysis as follows:-

Table 1 The Causes of Conflicts between Medical Doctors and the Government in Public Hospitals

\begin{tabular}{|c|c|c|}
\hline \multirow{6}{*}{$\begin{array}{l}\text { Category } \\
\text { Working } \\
\text { Environment }\end{array}$} & Theme & Findings \\
\hline & Working facilities & -No enough wards \\
\hline & & -No enough beds \\
\hline & & $\begin{array}{l}\text {-No enough diagnostic machines like x-rays, MRI, CT scans, } \\
\text { etc. }\end{array}$ \\
\hline & & -No enough ICU's for children \\
\hline & $\begin{array}{ll}\text { Unavailability } & \text { of } \\
\text { medicines } & \end{array}$ & $\begin{array}{l}\text {-Some medicines are unavailable in public hospitals that } \\
\text { patients have to buy them in private pharmacies. }\end{array}$ \\
\hline \multirow[t]{4}{*}{ Workload Policy } & Patient overcrowding & -Doctors attend a large number of patients per day \\
\hline & Shortage of staff (Dr's) & -No enough medical doctors in public hospitals \\
\hline & & -Some medical doctors refuse to go to remote areas \\
\hline & & -Public hospitals do not have enough specialists \\
\hline \multirow{3}{*}{$\begin{array}{l}\text { Human } \\
\text { Policy }\end{array}$} & Remunerations & -Medical doctors are lowly paid \\
\hline & Doctors promotions & $\begin{array}{l}\text {-Some medical doctors have to wait for more than } 5 \text { years to } \\
\text { be promoted }\end{array}$ \\
\hline & Medical Insurance Scheme & $\begin{array}{l}\text {-Some promotions are withheld for no reasons } \\
\text {-Doctors demanded that the current medical insurance } \\
\text { scheme in use restricts members to access some services }\end{array}$ \\
\hline
\end{tabular}




\section{International Journal of Business Management and Economic Review}

Vol. 3, No. $05 ; 2020$

ISSN: 2581-4664

\begin{tabular}{|ll|}
\hline \hline Hardship allowance & $\begin{array}{l}\text { example some expensive diagnostic lab tests. They wanted } \\
\text { that they should be allowed to all without restrictions } \\
\text {-The remotely placed medical doctors should be given or } \\
\text { rather considered for the hardship allowance to encourage } \\
\text { others to accept the placements and continue providing } \\
\text { services to patients. } \\
\text {-In treating the patients, doctors risk their lives to a great } \\
\text { extent as they can be infected easily if extra care has not } \\
\text { been exercised. } \\
\text {-They are lowly paid } \\
\text { Overtime allowance } \\
\text { Call allowances }\end{array} \quad$-They are not timely paid \\
& \\
\hline
\end{tabular}

Based on Table 1, a number of themes were developed from the study participants as collected from the field. Each category of the study is presented hereby, followed by the presentation of themes generated from participants.

\section{Working Environment}

Oludeyi (2015) defines the work environment as the physical settings, conditions, situations and circumstances under which people perform their daily or assigned duties. These are the general hospital settings, situations, conditions, and circumstances in which medical doctors perform their duties. In this regard, the two themes that were developed are the working facilities and the unavailability of medicines.

\section{Working Facilities in Public Hospitals}

The hospitals should have enough wards and beds for all patients, working diagnostic machines like x-rays, Magnetic Resonance Imaging (MRI), Computed Tomography Scan (CTscan), etc. The findings from the field suggest that the working environment among medical practitioner's specific medical doctors is not conducive. Some patients fail to be admitted to the respective wards because the wards are fully occupied and even if it's an emergency case and the patient has to be admitted regardless of the availability of hospital beds, then a patient sleeps on the floor. This reason was raised by all participants during the interview sessions. For example, one participant (P1) who is a medical specialist I from Muhimbili was asked about the causes of conflict had the following explanations:

“... Well, Muhimbili was established in 1956 to serve 300,000 people as the Dar es Salaam population during that time and now the city has more than 5 million people while the hospital has almost the same buildings. We are working in a very difficult environment as we don't have enough wards for patients and even what we have now are not in good condition at all, some patients with critical conditions fair to secure hospital beds to start treatment and that makes them sleep on the floor and occurs because everyone believes that since this is a national referral hospital then all the best doctors and facilities will be available..." (Interview, P1, May 2019).

From the extract, it can be argued that the working environment for medical practitioners in terms of facilities is not conducive. These findings are corroborated by other empirical studies 


\section{International Journal of Business Management and Economic Review}

Vol. 3, No. $05 ; 2020$

ISSN: 2581-4664

from other countries in Sub-Sahara Africa. For instance, a study by Hossain, (2017) revealed that creating a favorable atmosphere and work environment would enhance employee's performance in an organization. This indicates that creating a favorable work environment in terms of facilities or in other words providing work facilities to employees increases their work efficiency.

Another participant P2 had almost similar views as explained by P1 when she shared:

“.... We are working in a very difficult working environment, the facilities are not enough compared to the number of patients we receive on a daily basis and I think the government knows that, but the emphasis is on other sectors and not the health sector..." (Interview, P2, May 2019).

The participant shows the condition of the working environment in a public hospital. The quote indicates that Doctors were working with inadequate facilities in relation to the number of patients.

\section{Unavailability of Medicine}

Apart from the working environment, another theme is the unavailability of medicine. $85 \%$ of the participants mentioned the unavailability of medicine to be among the causes of conflict between doctors and the government. They explained that after attending patients and a thorough diagnosis of patient illness, they provide them prescriptions of medicine, which were claimed by pharmacists to be out of stock. It was revealed from the study that patients' complaints to doctors eventfully resulted in conflict between doctors and the government. While the former pressure the government to ensure the availability of medicines in hospitals the latter claims not to have enough funds for supplying enough medicine in hospitals. Sometimes patients are ordered to buy some medicines from outside pharmacies as they are not available in the hospitals. And this is not only for Muhimbili but to most of the public hospitals. Other participants had similar views on the unavailability of medicine, that there is a need to make sure that health services are provided in a good working environment and medicines are available. Deducing from the quotations it is clear that in Tanzania medical doctors are working in a very difficult environment, treating patients and prescribing medicines that are not available in their respective hospitals.

These findings are in consonance with the study by Isangula, (2012) and Kijo-Bisimba, (2012) that among other causes of the medical doctor's strike is the working environment. Having enough medicines helps medical doctors to work efficiently and prescribe relevant medicines to their patients. Public hospitals in Tanzania do not have enough medicines for sick people, and this gives them a very hard time when it comes to the general treatment of patients. This is supported by participant $\mathrm{P} 4$ who commented that:

“... We are working on a very difficult condition that you prescribe medicines to patients and yet to find out that they are not in the hospital pharmacy or they are not listed by national health insurance fund (NHIF) and that makes this job difficult... "(Interview, P4, May 2019). 


\section{International Journal of Business Management and Economic Review}

Vol. 3, No. 05; 2020

ISSN: 2581-4664

The quotation denotes that, public hospitals in Tanzania do not have enough medicines and that promotes the existence of private pharmacies around the hospitals for the medicines that are not available when prescribed.

\section{Workload Policy}

In order for the employees of any organization to work effectively and efficiently, then the right job should be performed by the right number of employees (Ngirwa, 2006). Allowing employees to be overloaded with work reduces their efficiency and performance as well.

\section{Patients Overcrowding in Public Hospitals}

In public hospitals, most of the patients attending are normal citizens looking for cheap and reliable medical services and that makes the public hospitals to be overcrowded with a large number of patients.

The findings from the field advocate that, Muhimbili as a national referral hospital experiences a large number of patients per day. Participants when they were asked about this question, almost all of them had similar comments on the aforementioned factor. Most of the patients had believed that since Muhimbili is a national referral hospital, then even their complex medical issues will get a better solution. Muhimbili receives more than 3,000 patients per day and yet the facilities are able to serve not more than 1,000 patients. For example participant P1, once she was asked about this question she had the following explanations:

"... We are getting a lot of patients from all corners of the country as this is the national referral hospital whereby all complex cases are referred to Muhimbili as a national referral hospital and yet the hospital has not been expanded to accommodate the patient's increment and even other services have not been expanded to fit the need..." (Interview, P1, May 2019).

This has been a cry of medical doctors that were interviewed in Muhimbili national hospital that some necessary measures should be taken to control the number of patients coming to the hospital as the available facilities cannot accommodate them.

Taking an example of $\mathrm{P} 1$ who depicted that:

“..Muhimbili was not established to serve more than 300,000 people, now Dar es Salaam has more than 5,000,000 populations and yet we are attending some other complex issues from all over the country and east Africa as a referral hospital with almost the same facilities and it reaches a day where you attend more than 200 patients a day as an individual, something that compromises the quality of service offered to patients..." (Interview, P1, May 2019).

The quote is an indication that the number of patients attending public hospitals is high and that even medical doctors cannot handle them efficiently. This might signify that the doctors may be overloaded with the work and that compromises the quality of service offered to patients. This coincides with a study by Chigozie, (2017) that providing unclear responsibilities compromises the service quality and customer satisfaction in an organization.

\section{Shortage of Medical Doctors in Public Hospitals}

Apart from patients' overcrowding, the other theme under the workload policy category was the shortage of staff (medical doctors) in public hospitals. Museru, (2013) argues that; the 


\section{International Journal of Business Management and Economic Review}

Vol. 3, No. $05 ; 2020$

ISSN: 2581-4664

doctor-patient ratio during the strike was 1:28,571 against the recommended UN ratio of 1:10,000. Nevertheless, the WHO, (2016) doctor-patient ratio in Tanzania was 1:20,000 against the recommended WHO ratio of 1:600 for developing countries and 1:300 for developed countries.

A study by Museru, (2013) revealed that a large number of medical doctors from Tanzania have fled to Southern African countries in search of greener pastures and that has left the country with few medical doctors for its public hospitals. Most of the public hospitals have an inadequate number of doctors and even specialists. Currently, all the medical schools in the country drop in the market nearly 500 qualified medical doctors where the private hospitals also choose from and others are employed by the government and work in public hospitals. Still, public hospitals in the country experience a shortage of manpower (Museru, 2013).

Findings from the study revealed that public hospitals do not have enough medical doctors and that jeopardize the quality of service offered to patients. For example, participant P1 indicates clearly that:

".... Because we don't have enough and a reasonable number of medical doctors, we have to attend more than 200 patients each per each day, something that compromises the quality of service we offer to our patients..." (Interview, P1, May 2019).

Another quote from P7:

“.... Because of a shortage of manpower in public hospitals, we have formed a team of doctors (specialists) who move around the country after every certain period to attend patients' complex matters because we know they cannot easily reach to referral hospitals due to various reasons...." (Interview, P7, May 2019).

These arguments suggest that there is a shortage of medical doctors in public hospitals compared to the number of patients.

Deducing from the quotations, it is that Muhimbili as a national referral hospital suffers the shortage of medical doctors something that compromises the quality of health services offered to customers. This concurs with the study by Museru, (2013) that revealed the whereabouts of medical doctors in Tanzania regardless of the fact that the government spends money and other resources in their training.

\section{Medical Doctors Remunerations}

Ngirwa, (2006) defines remuneration as a fair reward (financial or non-financial) for the labor input in an organization. That is what an employee receives as a result of his/her efforts in contributing to organizational performance. Medical doctors are the employees of public hospitals and that findings from the field suggest that, medical doctors are not satisfied with their salaries and other benefits. They are complaining that they are doing a very risky and difficult job and yet their salary is not proportional to the work done. Despite the fact that medical doctors are among the highest-paid professionals in Tanzania, the medical doctors still think they salary increments to match the job they do. 


\section{International Journal of Business Management and Economic Review}

Vol. 3, No. $05 ; 2020$

ISSN: 2581-4664

This has been the concern of all participants in the study and some even went further, saying the government does not care for their wellbeing for example participant P2 said:

"...... We are not paid well and the government does not care at all, we know it's not easy to increase all the government employees, but at least they could have given health workers a priority........" (Interview, P2, May 2019).

Another respondent $\mathrm{P} 4$ added that:

“...... The government has to be a little bit considerate when it comes to our salaries; we are not well paid compared to medical doctors of the same qualification with us in other countries of Africa or even outside Africa.....” (Interview, P4, May 2019).

Deducing from the quotations, it can be argued that the medical doctor's salaries should be restructured to match the job they do and to reduce these ill-feelings from medical doctors. In addition to that employee's salary should itself act as a motivating factor towards better job performance in an organization, this means the remuneration itself has to motivate the working medical doctors in public hospitals and induce and revive their working spirit. The findings concur with a study by Chigozie, (2017) which revealed that poor reward system acts as a catalyst to organizational conflict and the vice versa of it acts as a motivation factor to employee job performance. Reasoning from the study findings, this has been a cry of medical doctors for a long period of time expecting the government to hear and work on it but it is not what they think at all. $100 \%$ of the participants mentioned this as one of the causes of conflict.

\section{Medical Doctor's Promotions}

Promotion is in effect a transfer involving the reassignment of an employee to a position that is likely to offer higher remuneration, greater responsibilities, privileges, and potential opportunities (Ngirwa, 2006). Generally, the purpose of a promotion is to staff a vacant position that is worth more to the organization than the employee's current position - the additional worth usually reflected in the form of additional duties, responsibilities, pay, privileges and potential opportunities for the position.

Another demand of medical doctors was that they stay for so long without being promoted to relevant positions despite the fact that they have the needed qualifications. Deducing from the responses of participants, it was noted that this was among the demands of many participants, especially specialists who claimed to have acquired the needed qualifications (educational and experiential) but yet they haven't been promoted.

For example participant, P7 claimed that:

“....I have acquired the needed educational and experiential qualification and haven't been promoted, and I don't understand why and even when I make some follow-ups I fail to get satisfactory answers....."(Interview, P7, May 2019). This was also a cry of participant P3, P4, P6, P9, and P22 as they provided almost similar opinions on the subject matter.

From the quote it is seen that the promotion issue in public hospitals has been a problem for medical doctors and even when they make follow-ups on the subject matter, no convincing answers are given to them. In practice, employee promotions are among the factors that increase 
Vol. 3, No. 05; 2020

ISSN: 2581-4664

job performance in organizations. Public servants have not been timely promoted. This is inconsonant with a study by Nehemia (2017) who highlighted promotional problems facing public servants in the Igunga district. Also, studies by Anangisye (2010); Ndikumwami (2013) and Rugaimukamu (2014) focus on teacher's promotional matters or problems as a public servant. Medical doctors are also public servants and are still trailing in the same route of not being promoted timely.

\section{Medical Insurance Scheme for the Doctors}

A medical insurance scheme is a system designed to finance medical expenses by means of contributions paid into a common fund for the purpose of covering health services specified in the insurance scheme. Like any other public servant in Tanzania, medical doctors are under the National Health Insurance Fund for their medical issues. Medical doctors demanded to have a medical insurance scheme that will allow them to get medical treatment and other medical services without restrictions. The National Health Insurance Fund of Tanzania has the responsibility of providing health insurance services to all government employees including all medical doctors from public hospitals. According to Kumburu, (2015) health insurance scheme is defined as insurance against the risk of incurring medical expenses among individuals by estimating the overall risk of health care and health system expenses, among a targeted group. An insurer develops a routine finance structure, such as a monthly premium or payroll tax, to ensure that money is available to pay for the health care benefits specified in the insurance agreement. The medical insurance scheme covers the principal member, spouse and four children below 18 years and if above 18 years then have to be in school whereby a member contributes $3 \%$ of his/her salary as a monthly contribution for that.

Apart from such contributions and other issues in the medical insurance scheme, the doctors demanded that the current medical insurance scheme in use restricts members to access some services example some expensive diagnostic lab tests and medicines. Their demand was that they should be allowed to everything without restrictions as they are the ones who are providing health care services to patients as participant $\mathrm{P} 4$ added that:

"...Members of parliaments are allowed to everything when it comes to medical insurance here in Tanzania but we doctors who are attending them are restricted to some, what does it mean? We are demanding that the responsible people in NHIF work on that and allow us to access all the services and even medicines..." (Interview, P4, May 2019).

The findings indicate that the doctors were not satisfied with the NHIF policy that they were restricted from some medical services while in practice they are the ones who provide them to the patients. The doctors seemed to believe that since they were responsible for health service provisions in the country, then they shouldn't be restricted from some medical services. The findings thus suggest a team of NHIF officers to discuss the matter with the representatives of theMedical Association of Tanzania (MAT) (on behalf of medical doctors) and agree on some important terms that brought about the conflicts. 


\section{International Journal of Business Management and Economic Review}

Vol. 3, No. $05 ; 2020$

ISSN: 2581-4664

\section{Medical Doctor's Allowances}

The problem of medical doctor's allowances (hardship, overtime, and call) was discussed. The doctors suggested that the government should think of imposing the hardship allowance to remotely placed medical doctors at least to enable them to continue staying there. This would suggest that if not well handled only few medical doctors would stay there and that would jeopardize the general provision of medical services to innocent citizens.

This was supported by participant $\mathrm{P} 2$ that:

".....There are no enough doctors in remote areas because every doctor wants to stay in urban areas to tap the opportunities that may arise, rather than staying in remote areas for nothing....." (Interview, P2, May 2019).

Another participant $\mathrm{P} 3$ added that:

"...The only motivator for a doctor who stays in remote areas is the introduction of hardship allowance that would make them feel that they have something extra comparing to those working in cities..... "(Interview, P3, May 2019).

The findings indicate that the introduction of hardship allowance would enhance doctors working spirit and enable them to work in remote areas without hesitation. The findings thus call for implementation of Isangula (2012)'s study that negotiation between the parties involved in conflict would produce fruitful results as all the financial matters were among the agenda during the negotiations. That the employer should negotiate with the employees (Doctors) to discuss their needs and challenges in their working environment.

\section{Medical Doctors Overtime Allowance}

The overtime allowance is the type of allowance that an employee receives after working beyond the normal hours of work as a result of having more work to do. This has been a cry for medical doctors, that they normally work beyond normal working hours but the overtime is not paid to them and even if it is paid, it is lowly paid. This is cemented by participant P4, who said:

"...The overtimes are so hard to be paid to us that sometimes we even don't see the reason for requesting it, even when it is paid, it is a very small amount of money that does not add anything to the receiver..." (Interview, P4, May 2019).

Another participant $\mathrm{P} 6$ added that:

"...We would like to see that the amount paid is a reasonable amount, rather than paying just a very small amount or if they think it is not important, it is better if they just remove that from the compensation policy that we have..."(Interview, P6, May 2019).

Deducing from the quotes above, it has been revealed that the overtime allowance for medical doctors is not enough and that it has to be increased. This is supported by a study by Isangula, (2012) who cemented that the conflict was a result of unfruitful negotiations between the parties involved and one of the issues that were under the negotiations was the medical doctor's allowances. 


\section{International Journal of Business Management and Economic Review}

Vol. 3, No. $05 ; 2020$

ISSN: 2581-4664

\section{Medical Doctors Call Allowance}

Call allowance is another theme under the category of human resources policy. It is a type of allowance that is paid to compensate an employee for being on duty call in an organization (Ngirwa, 2006). Medical doctors are claiming that the amount paid to them when they are on call is so small and that it is not paid to them timely regardless of the fact that they are working in a very risky working environment. This is supported by participant P1 who said:

“...We are paid a call allowance, but it is just a small amount that does not relate to what we are doing at all. You stay at home and being called for a case that needs your expertise at night you wait for a car to pick you up for about 2 hours and after you are paid a very small amount of money as call allowance..."(Interview, P1, May 2019).

This was also supported by other participants who generally commented that:

"...We are not well paid when it comes to calling allowances as we are spending more than 4 hours attending an emergency at night and at the end, we are paid a tiny amount of money for that ... "(Interview, doctors, May 2019).

Construing from the above quotations, the amount paid as call allowance to medical doctors is small and that they are not satisfied with it.

Conclusively, we have seen the participants explaining the causes of conflict in public hospitals. It was not possible to attend to all the causes at once, but the government could have conducted a series of meetings with the medical doctors discussing these causes and their possible solution.

This is supported by participant P2, P3 and P6 who said that:

"....We know that the government couldn't have solved all the issues we raised, but we expected them to use integrating or compromising approaches of dealing with the problem. They could have convened several meetings with us and agree on the modality of attending to our demands, but instead they just forced and threatened us...." (Interview, doctors, May 2019).

From the findings, it was not possible to solve all the raised causes, but the government would have prioritized the causes and agree with medical doctors on which one to come first and with time all raised issues would have been attended.

\section{CONCLUSION AND RECOMMENDATIONS}

Theoretically, the study contributes and adds more inputs on the theory that guided this study. The findings of the study add a new perspective on the underlying assumptions of the contingency theory of conflict management. That management of conflicts and especially in public hospitals in developing countries would require considerations and fulfillment of medical doctors' needs as they predict the work morale and job performance in particular. The general assumption of the theory is that once conflicts at workplaces an analysis of the conflict situation is needed so as to suggest a relevant conflict management approach. 


\section{International Journal of Business Management and Economic Review}

Vol. 3, No. $05 ; 2020$

ISSN: 2581-4664

The theory is silent about these aspects of identification of the causes of conflict and their contribution toward a sustainable medical doctor's job performance. In managing conflicts, the causes of conflicts should be identified first as it would enable to understand the conflict's nature and how it will be managed.

The findings revealed that working facilities, unavailability of medicines, Patient overcrowding, Shortage of staff, Remunerations, Doctors promotions, Medical Insurance Scheme, Hardship allowance, Overtime allowance, and Call allowances were the major causes of conflict in public hospitals. Basing on the causes of conflict between medical doctors and the government in public hospitals in Tanzania, it is concluded that the conflict could have been managed if the government was to allow a series of meetings and not to force medical doctors to continue to work even at the time where things were not going well between the parties. And therefore the integrating and compromising approaches of managing conflict were proposed.

The findings suggested that if the government could have been ready to discuss the issues with them and solve the raised problems one after the other, with time the strike couldn't have been there. However, seemed the employer preferred force instead of taking Doctors' demands into consideration.

Nevertheless, it is not easy to accept all the demands, especially on the side of the employer (i.e. The government) but there could be some series of discussions as Isangula (2012) identified that if there were no negotiations between the parties, thus brought about the strike. This is in congruence with the current study as the causes were mentioned by the participants and respondents, and that the government could work on them to improve the health service provision to the general public. These findings indicate that respondents agreed on the causes of conflict identified and are dissatisfied with the measures taken by the government to handle the conflict in public hospitals. It can be concluded that in a conflict situation the parties in conflict were to sit and examine issues at hand before reaching a probable solution and were supposed to be ready to integrate and compromise with the other part in a conflict situation.

\section{Limitations of the Study}

This research was conducted in two public hospitals, which are Muhimbili National hospital and Dodoma Referral Regional Hospital in Tanzania. Muhimbili has been reported as the center of the doctors' strikes in Tanzania. Muhimbili is the Major referral hospital in Tanzania and it is where strikes start all the time, while Dodoma Regional Referral Hospital is amongst the regional referral hospitals where the strike spread and since it has the same rank or it is on the same level with other regional hospitals of Mwanza, Kilimanjaro and Tanga, the researcher decided to take it into the study to represent other regional referral hospitals in Tanzania rather than studying all other four regional hospitals. The study intended to address the influence of conflict management on the medical doctor's job performance in Muhimbili national hospital and Dodoma regional referral hospital, Tanzania.

The findings of this study cannot be transferred to other sectors if they are in a conflict situation, but rather a study of this nature can be conducted to other sectors to get results. The study 


\section{International Journal of Business Management and Economic Review}

Vol. 3, No. 05; 2020

ISSN: 2581-4664

encountered some limitations like some delays in getting data collection permits from respective public hospitals. But finally, the researcher secured permission to collect data and the study went as planned. Also, the study focused only on medical doctors, leaving aside other health workers like nurses and medical officers, further studies could focus on these other health workers and other public sectors.

The findings under this study indicated that ineffective management of Doctors' poor working environment (i.e. few/poor working facilities, unavailability of medicines, patients overcrowding, shortage of staff (Doctors), remunerations, doctors promotions, medical insurance scheme, hardship allowance, overtime allowance and call allowances) was the main cause of conflict between medical doctors and the government. This study thus calls for effective management of Doctors' needs for their well-being and hospitals' performance in general.

\section{REFERENCES}

Agwu, M. O. (2013). Conflict management and employee performance in Julius Berger Nigeria Plc. Journal of Human Resources Management and Labor Studies. Bonny Island, 1(1), 34-45.

Ajike, E. O., Akinlabi, B. H., Magaji, N., \& Sonubi, A. O. (2015). Effect of conflict management on the performance of a financial service organization. In Nigeria: An Empirical Study of Access Bank Plc, International Journal of Economics, Commerce and Management, 3(7), 260-272.

Ali, M. (2016). The role of conflict management in organizational performance Case Study: Somali National University. High-quality Research Support program (HQRS).

Al-Hamdan, Z., Shukri, R., \& Anthony, D. (2011). Conflict management styles used by nurse managers in the Sultanate of Oman. Clinical Nursing, 20, 71-580.

Anangisye, W. A. L. (2010). Promoting teacher ethics in colleges of teacher education in Tanzania: practices and challenges. African Journal of Teacher Education, 1(1), 64-77.

Blank, S. (2020). Managing Organizational Conflict. North Carolina. McFarland \& Company, Inc

Chigozie, N. E., (2017). Impact of Organizational Conflict on Employee Job Performance in Selected Hotels (in Lagos Nigeria). TURIZAM. 21(1), 45-64.

Creswell, J. W. (2009). Research design: Qualitative, quantitative, and methods approach. (3rd edition). California: Sage Publications Ltd.

Creswell, J. W. (2014), Research design qualitative, quantitative, and mixed methods approach, (4th edition). Los Angeles: SAGE Publications, Inc.

Dunnette, M. D. (1998). The handbook of industrial and organizational psychology, (2nd edition). California: Davies-Black Publishing.

Ebtesam, S. A. A., Aya G. H. G. (2018). The Effect of Conflict Management Program on Quality of Patient Care. American Journal of Nursing Science. 7( 5), 192-201.

Eisenberger, R., Huntington, R., Hutchison, S. \& Sowa, D. (1986). Perceived organizational support. Journal of Applied Psychology, 71 (3), 500-507.

Furumo. (2008). The impact of conflict and conflict management style on deadbeats and deserters in virtual teams. Hawaii International Conference on System Sciences, 1-10. 


\section{International Journal of Business Management and Economic Review}

Vol. 3, No. $05 ; 2020$

ISSN: 2581-4664

Gull, S., Rehman, H., and Zaidi, S.F.B. (2012). Impact of conflict management styles on team effectiveness in the textile sector of Pakistan. International Journal of Business and Management, 7(3), 219-229.

Hossain, Z. (2017). The impact of organizational conflict on employees' performance in private commercial banks of Bangladesh. Journal of Business and Management, 19(10), 12-21.

Isa, A. A.,(2015). Conflicts in Organizations: Causes and Consequences. Journal of Educational Policy and Entrepreneurial Research (JEPER), 2(11), 54-59

Isangula, K. G. (2012). Activism during doctor's strike in Tanzania, success and Setbacks, Sikika Journal.

Kazimoto, P. (2013), Analysis of conflict management and leadership for organizational change, International Journal of Research in Social Sciences, 3(1)

Khan, K., Hussainy, S. K., Iqbal, Y. (2016). Causes, effects, and remedies in conflict management. The South East Asian Journal of Management, 10(2), 152-172.

Kijo-Bisimba, H. (2012). Status of doctor's strike and the right to life, LHRC, Dar es Salaam: Unpublished.

Kothari, C. R. (2004). Research methodology; methods \& techniques, (2nd edition), New Delhi: New Age International (P) Limited.

Medical Association of Tanzania (MAT) (2012). What behind doctors strikes in Tanzania?, Dar es Salaam, Jamana Printers.

Museru, L. M. (2013). Tanzanian Doctors where are they? Muhimbili Orthopedic Institute, MAT - AGM

Ndikumwami, M., (2013). Investigation of challenges that face teachers in improving teaching performance in primary schools: a case of Dodoma municipal council, Open University of Tanzania, Tanzania. 93pp

Nehemia, A., (2017). Effectiveness of employees' promotion procedures in the public sector: a case of Igunga local government authority, Mzumbe University, Tanzania. 83pp

Ngirwa, C. A. (2006). Human resources management in African work organizations, Vol 1, Dar es Salaam: National Printing Corporation (NPC)

Ngirwa, C. C., Euwema, M., Babyegeya, E., \& Stouten, J. (2012). Leader's styles of managing conflicts in change initiatives, Social Science Research Network-SSRN, 1-27.

Olang, B. A. (2017). The influence of conflict management on organizational performance: A case of stima Sacco society limited, Chandaria School of Business, United States University.

Oni-Ojo, B. E., Iyiola, O.O., \& Osibanjo, A. O. (2014). Managing workplace conflicts in a business environment: The role of alternative dispute resolution (ADR), European Journal of Business and Management, 6(36).

Pavlakis, A., Kaitelidou, D., Theodorou, M, \& Galanis, P, (2011). Conflict management in public hospitals: The Cyprus case, international Nursing Review, 58(2), 242-248

Pitsillidou, M., Farmakas, A., Noula, M., \& Roupa, Z. (2018). Conflict management among health professionals in hospitals of Cyprus, Journal of Nursing Management, 1-8. DOI: 10.1111/jonm.12631

Preacher, K. J., \& Hayes, A. F. (2008). SPSS macro for multiple mediations. Written by Andrew F. Hayes, The Ohio State University. http://www.afhayes.com/ 
International Journal of Business Management and Economic Review

Vol. 3, No. 05; 2020

ISSN: 2581-4664

Rahim, M. A. (2001). Managing conflict in organizations. (3rd edition). Westport, Connecticut: Greenwood Publishing Group, Inc.

Rahim, M. A. (2011). Managing conflict in organizations. (4th edition). New Jersey: Transaction Publishers.

Rugaimukamu, N. W., (2014). The challenges facing primary school teachers in teaching health education in Temeke municipality Dar es Salaam Tanzania, Muhimbili University of Health and Allied Sciences, Dar es Salaam. 